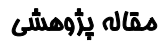

حذف نيترات از محلولهاى آبى با استفاده از بيو جاذب مخمر ساكاروميسس سرويسيه: ايزوترم و سينتيك جذب

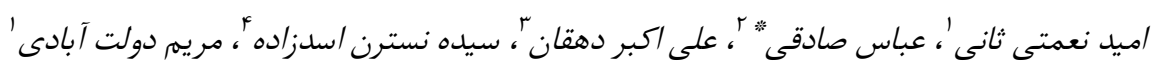

' دانشجوى كارشناسى ارشد مهندسى بهداشت محيط، كميته تحقيقات دانشجويى، دانشكده بهداشت، دانشعاه علوم يزشكى مشهيد، مشهرد، ايران

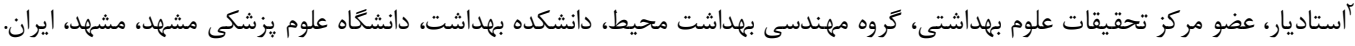

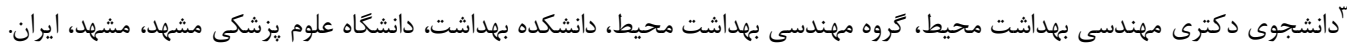

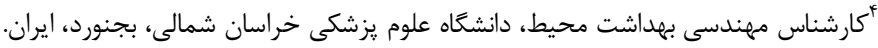

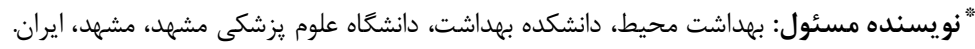

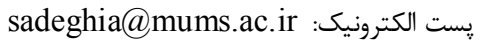

وصول:r/r/r/

جكيده

زمينه و هدف: نيترات يكى از آلاينده هاى آب آشاميدنى است. غلظت بالاى نيترات در منابع آب، يك خطر جلى محسوب مى شود

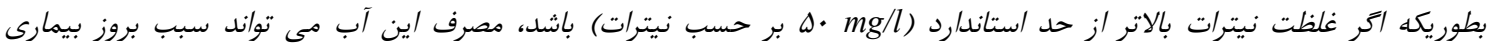

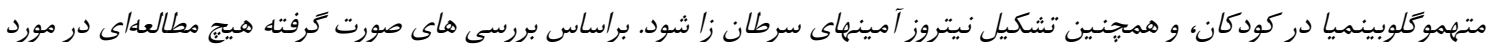

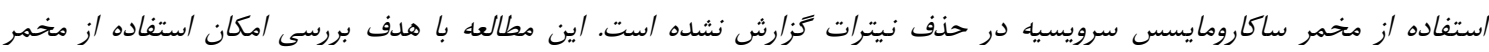

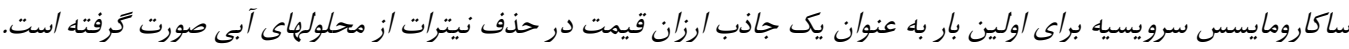

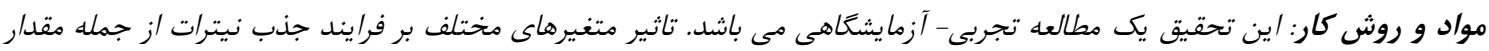

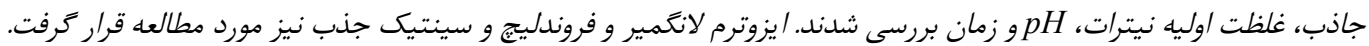

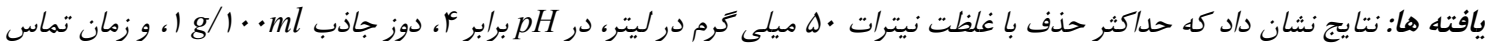

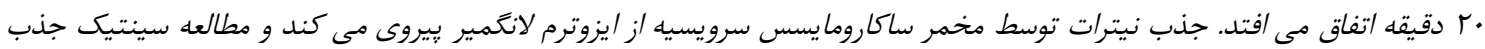

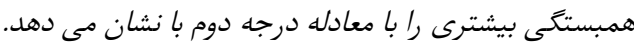

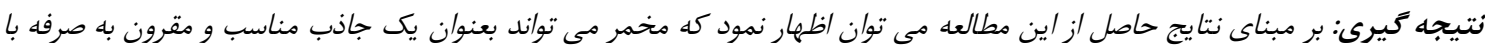
حداقل تكنولوزى در حذف نيترات مورد استفاده قرار كيرد. وازه هاى كليدى: نيترات، مخمر ساكاروما يسس سرويسيه، محلولهاى آبى، سينتيك، / يزوترم

زيرزمينى به نيترات مى توان گِساب ها، فاضلاب ها و و

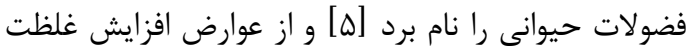

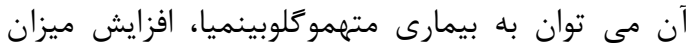

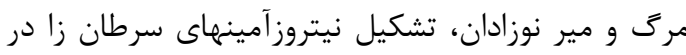

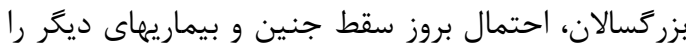

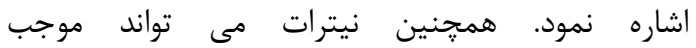

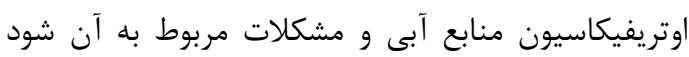

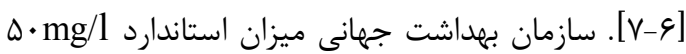

مقدمه نيترات يكى از آنيون هاى معدنى است كه در نتيجه اكسيداسيون نيتروزن عنصرى حاصل مى شود. اين ماده يكى از عناصر بسيار ضرورى براى سنتز يروتئين در

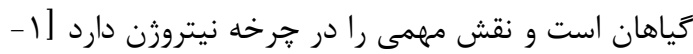

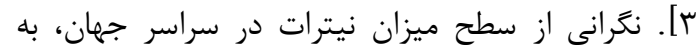
دليل كاهش كيفيت آبهاى سطحى و زيرزمينى در جهران ليترات

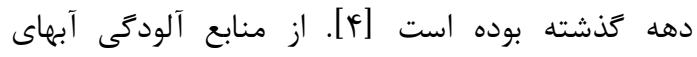


توان به مقدار زياد به عنوان يك محصول در صنعت توليد

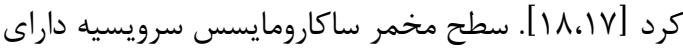

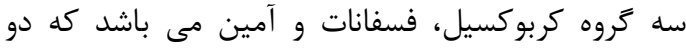
كروه كربوكسيل و فسفانات داراى بار منفى و كروه آمين داراى بار مثبت مى باشد. كروههاى آمين بطور عمده در درد

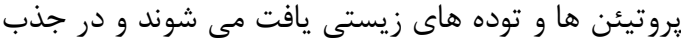

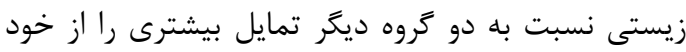
نشان مى دهد. همجنين در pH اسيدى گروه دره دآمين موجود در ديواره مخمر بيشتر تجزيه شده و تعداد بار

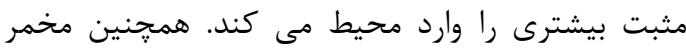

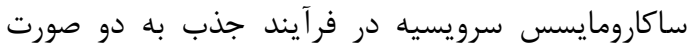

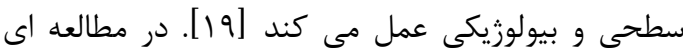
كه در مكانهاى آلوده به فلزهاى سنَّين انجام شد مشاهده

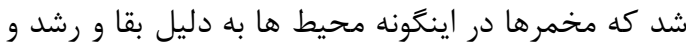
ظرفيت بالاى اتصال فلز به ديواره سلولى آنها و ميزان بالاى جذب درون سلولى، نسبت به ساير ميكروار كانيسمها

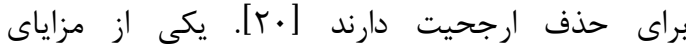

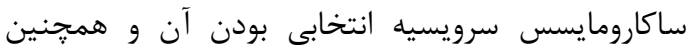

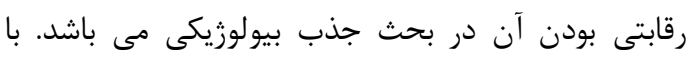

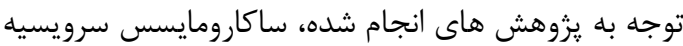
راندمان متوسطى را در جذب بيولوزيكى فلزهاى يك يا ليا

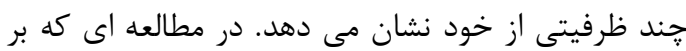
روى سموم آفلاتوكسين انجام شد مشاهده شد كه مخمر

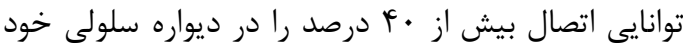

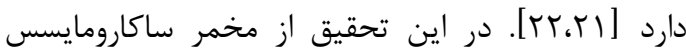

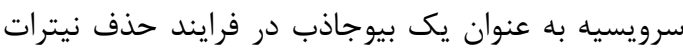

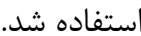

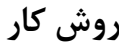
مطالعه حاضر در مقياس آزمايشحاهى و به صورت ناييوسته انجام شد. مخمر ساكارومايسس سرويسيه از شركت خمير مايه رضوى تهيه و ساير مواد شيميايى از شركت مرك سكان

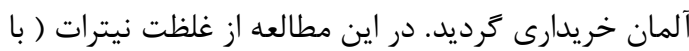
استفاده از

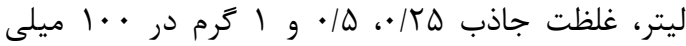

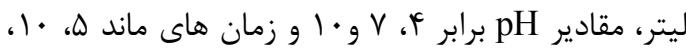

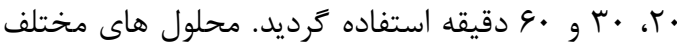
نيترات بروى دستخاه شيكر با سرعت •ها دور در دقيقه الهال
غلظت نيترات را در آب هاى آشاميدنى كه به صورت

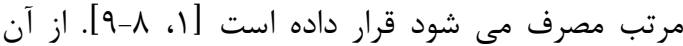

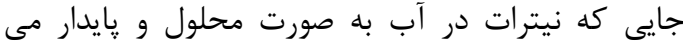
باشد روش هاى معمول تصفيه آب از جمله كلريناسيون، انعقاد و فيلتراسيون براى حذف اين ماده از آب مناسب

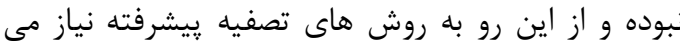

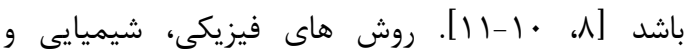
بيولوزيكى مختلفى براى حذف نيترات وجود دارد از جمله

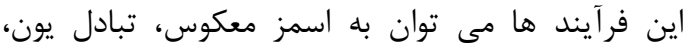
كلريناسيون نقطه شكست، الكترودياليز و دنيتريفيكاسيون

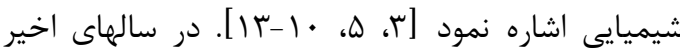
توجه فراوانى به مواد كم هزينه نظير يوست درخت، نانو التها

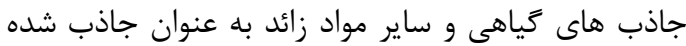

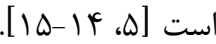

در مطالعه اى كه توسط فراستى و همكاران با عنوان استفاده از نانو جاذب هاى كياهى به منظور حذف نئ نيترات

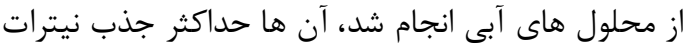

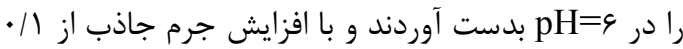

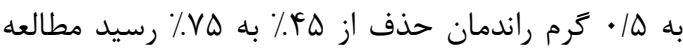

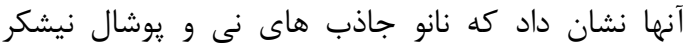

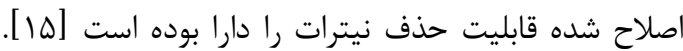
در مطالعه ديخرى كه با عنوان حذف نيترات توسط فرايند

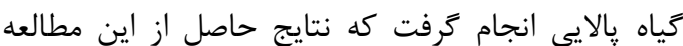

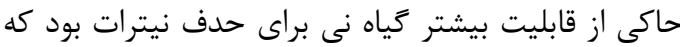

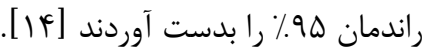
در مطالعه اي كه توسط رحمانى و همكاران با عنوان حذف آندان

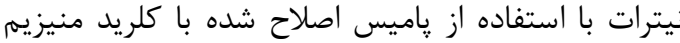

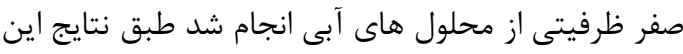

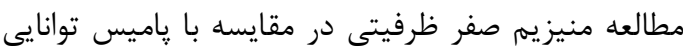
بيشترى براى حذف نيترات دارد اما اين عملكرد به شدات

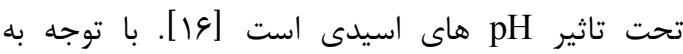
مطالعات صورت كرفته كه از روش هاى جذب سطحى و بيولوزيكى براى حذف نيترات استفاده شده روش هاى بيولوزيكى راندمان بالاترى دادند. ساكارومايسس سرويسيه به طور كسترده الى در توليد مواد داد داد غذايى و آشاميدنى استفاده مى شود و با توجه به راحتى آنى كشت اين اركانيسم و دستكارى سطح مولكولى آن مئى آنى 
رسيده است (نمودارهاى ا تأF) و با افزايش pH راندمان

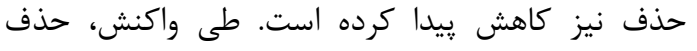

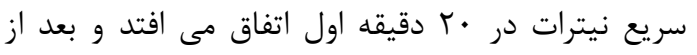

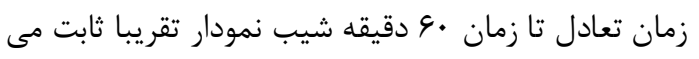

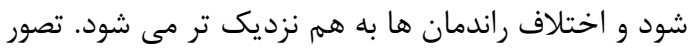

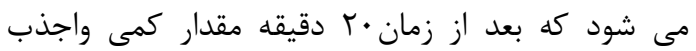

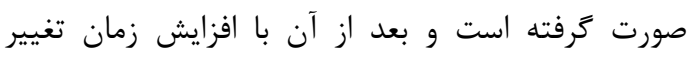
مشهودى در جذب صورت نكرفته است. بنابراين مخمر

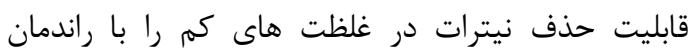

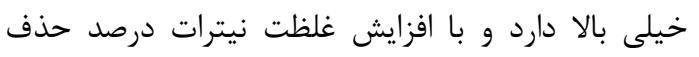

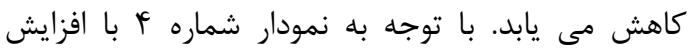

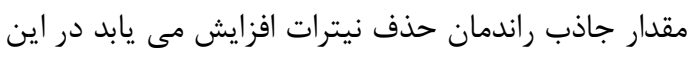

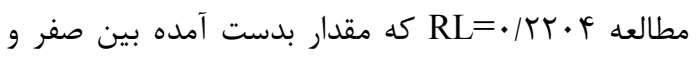

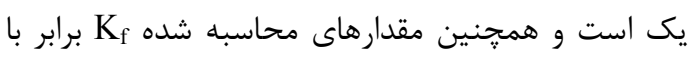

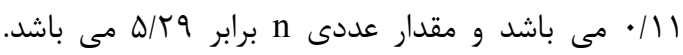
مطالعه سنتيك جذب نشان داد كه جذب نيترات توسط

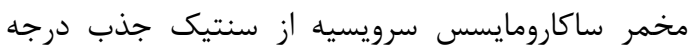

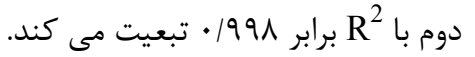

در معرض غلظت هاى مختلف جاذب قرار كرفت. بعد از طى زمان ماندهاى لازم براى جداسازى جاذب از داز دستخاه

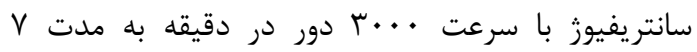

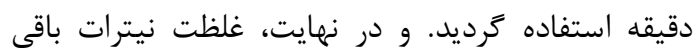

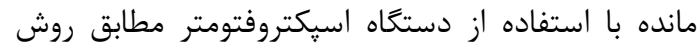

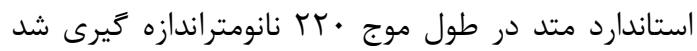

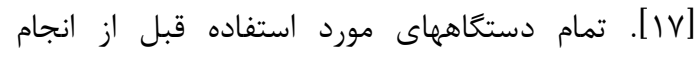

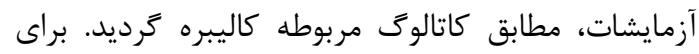

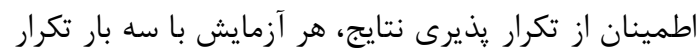

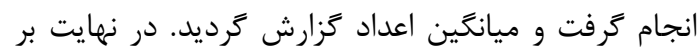

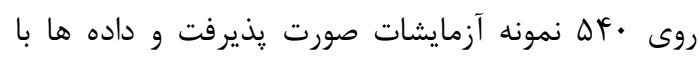

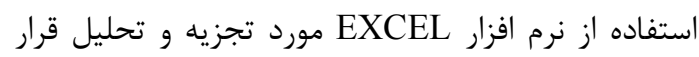

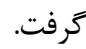

يافته ها نتايج نشان مى دهد كه در زمان · · دقيقه و شرايط

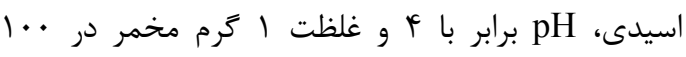

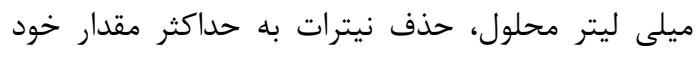

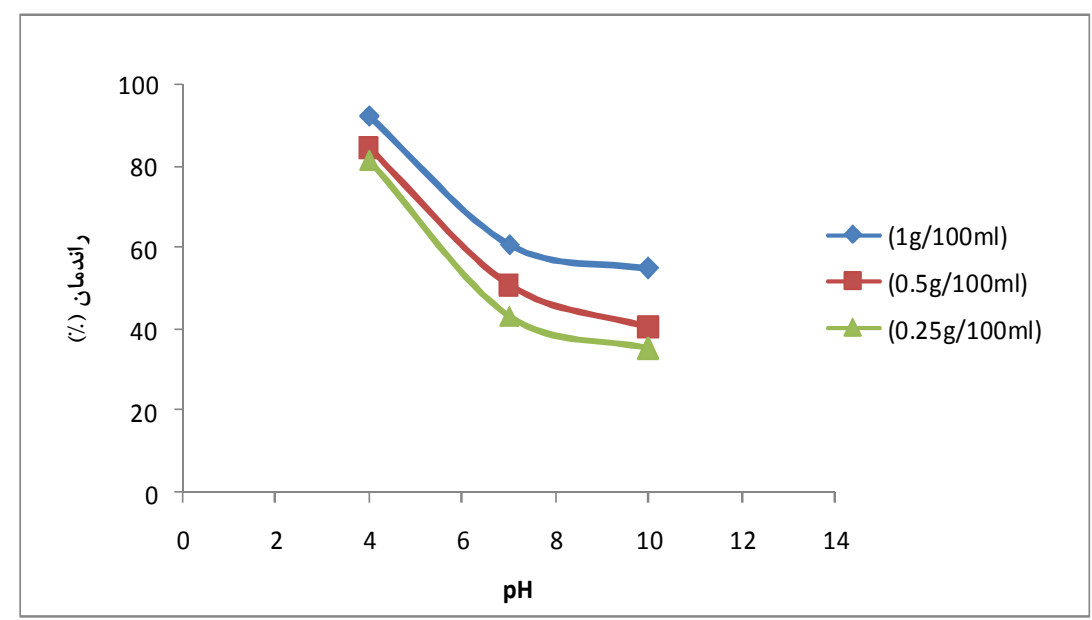

نمودار 1: تاثير pH بر راندمان حذف نيترات توسط مخمر ساكارومايسس سرويسيه (زمان ماند

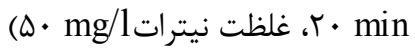




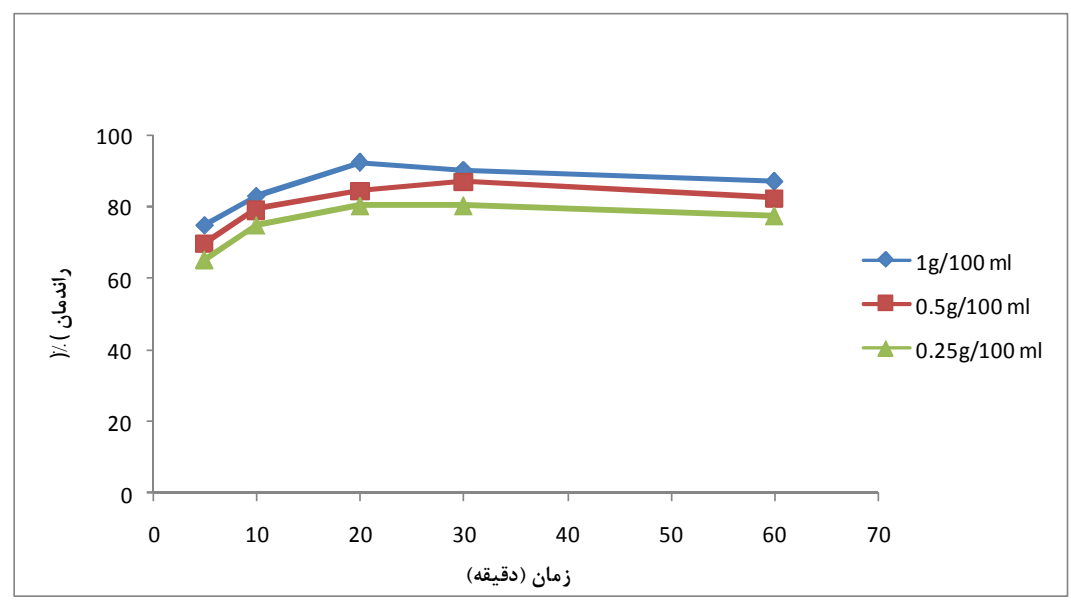

نمودار r: تاثير زمان ماند بر راندمان حذف نيترات توسط مخمر ساكارومايسس سرويسيه

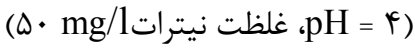

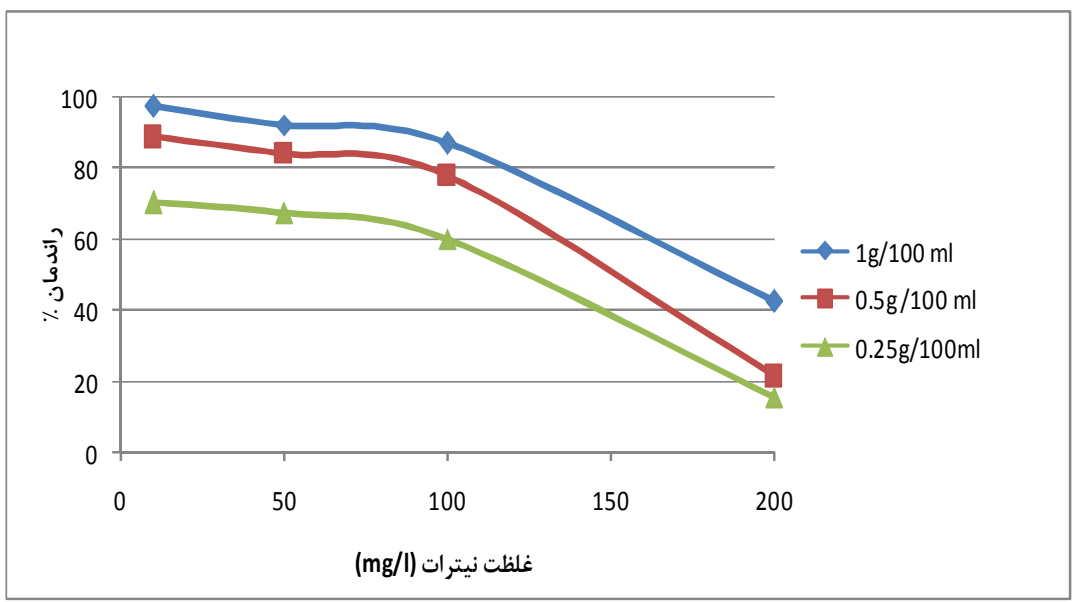

نمودارسا: تاثير غلظت نيترات بر راندمان حذف نيترات توسط مخمر ساكارومايسس سرويسيه

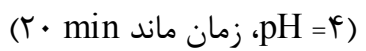




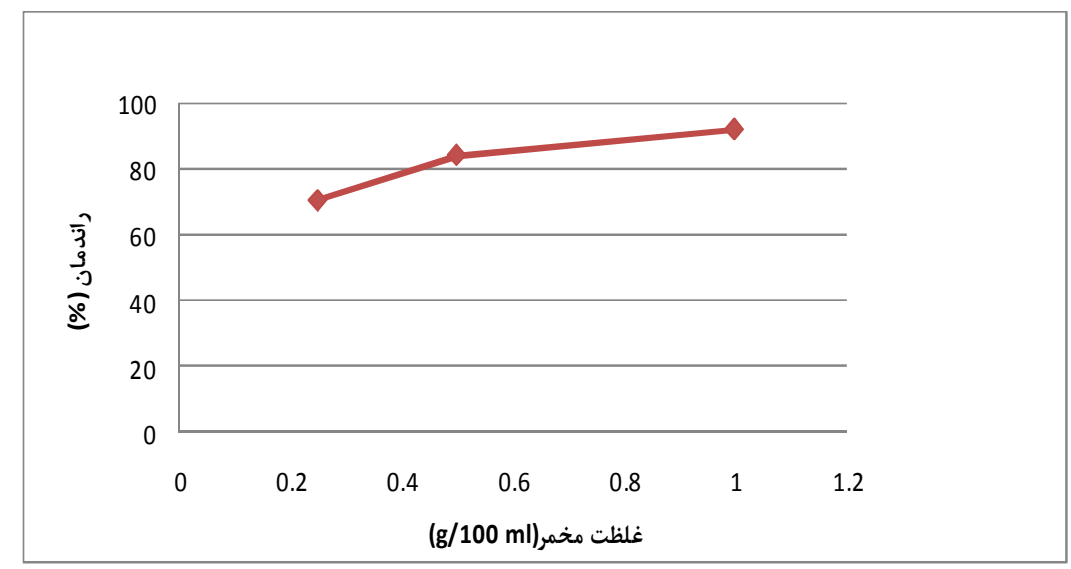

نمودار fا: تاثير غلظت جاذب بر راندمان حذف نيترات توسط مخمر ساكاروكايسس سرويسيه

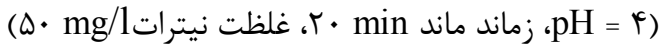

\begin{tabular}{|c|c|c|c|}
\hline \multicolumn{2}{|c|}{ فروندليج } & \multicolumn{2}{|c|}{ لانغمير } \\
\hline$\overline{K_{f}}$ & .111 & $\mathrm{~b}$ & $1 / \cdot V$ \\
\hline $\mathrm{n}$ & $\Delta / r_{q}$ & $\mathrm{q}_{\mathrm{m}}$ & $\Lambda / T q \Lambda$ \\
\hline $\mathrm{R}^{2}$ & •lATr & $\mathrm{R}^{2}$ & .1994 \\
\hline
\end{tabular}

سايت هاى فعال موجود در جاذب (كروه هاى آمين)

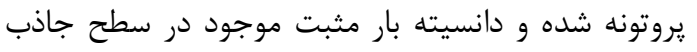

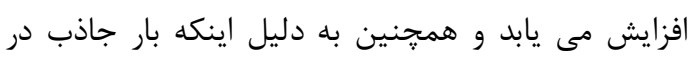

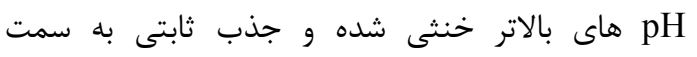

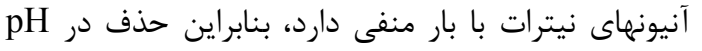

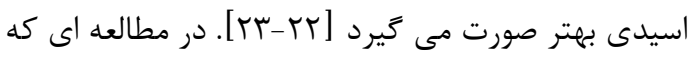
حذف نيترات توسط زئوليت اصلاح شده با سورفاكتانت

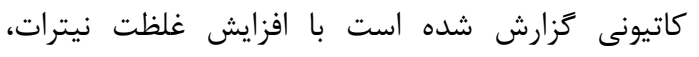

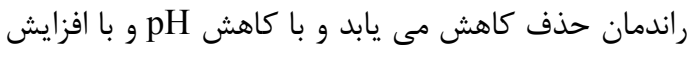
غلظت جاذب و زمان تماس راندمان حذف افزايش مي يد يابد

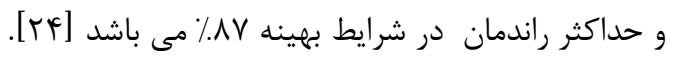

بحث تاثير pH در حذف نيترات با مخمر: مقدارpH محلول از

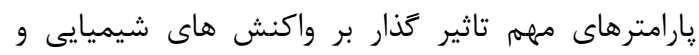

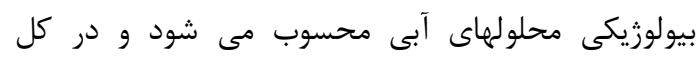

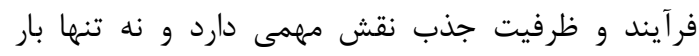

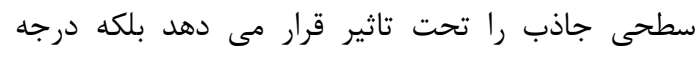

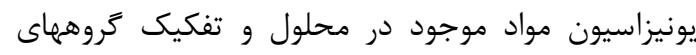

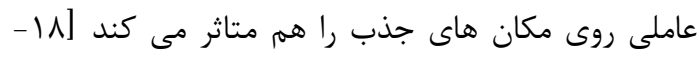

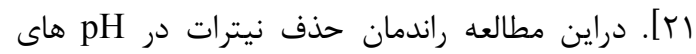

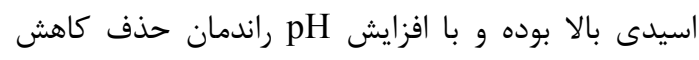

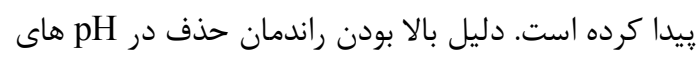

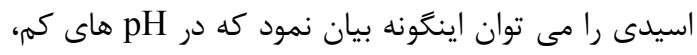


شونده به ازاى واحد جرم ماده جاذب استفاده مى شوند. معادله خطى ايزوترم لانغمير به صورت معادله (1) مى (1)

$$
\frac{c_{g}}{q_{g}}=\frac{1}{b q_{m}}+\frac{c_{g}}{q_{m}}
$$

در اين رابطه qe مقدار جزء جذب شده در جرم جسم جاذب بر حسب mg/g و qm نشان دهنده ظرفيت جذب، غلظت تعادلى ماده جذب شدنى در محلول بعد از

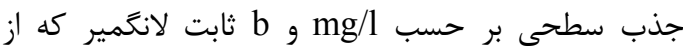

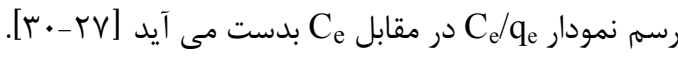
يكى از ويزگىى هاى معادله لانگمير، يارامتر بدون بعد

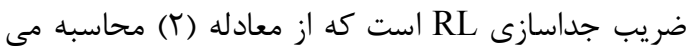

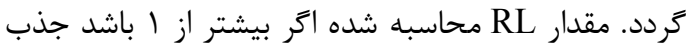
غير مطلوب، اگر برابر ا باشد جذب خطى، اگر صفر باشد

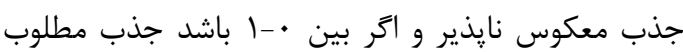

$$
R L-\left(\frac{1}{1+2 L s}\right)
$$

مدل فروندليج بر اساس جذب تك لايه ای بر روى مكان

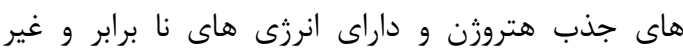
همسان بنا نهاده شده است. بله عبارت ديخر معادله فروندليج جذب را در يك سطح ناهمگون از نظر انرزى

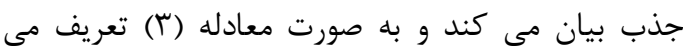

$\log \mathrm{q}_{\mathrm{e}}=\log \mathrm{K}_{\mathrm{f}}+1 / \mathrm{n} \log \mathrm{C}_{\mathrm{e}}$

كه Ce غلظت تعادلى در محلول بعد از جذب سطحى بر حسب ميلى گرم در ليتر و qe ظرفيت جذب در زمان تعادل (ميلى گرم بر زرم) و هستند. در ايزوترم فروندليج زمانى كه K افزايش مي يابد ظرفيت جذب جاذب براى جذب ماده جذب شونده مورد نظر

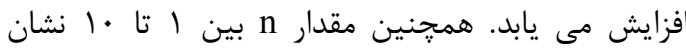

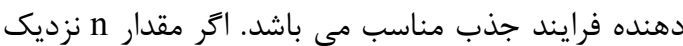
به ا باشد هتروزن بودن سطح كم اهميت تر و اگر نزديك

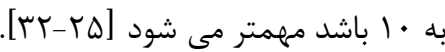

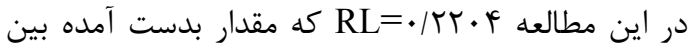
صفر و يك است. بنابراين فرايند جذب نيترات روى جاذب مورد مطالعه مطلوب مى باشد. و همجنين مقدارهاى
تاثير زمان تماس در حذف نيترات با مخمر:مقدار نيترات حذف شده تابعى از زمان تماس مى باشد. همانطور كه نمودار r نشان مى دهد YY\% حذف نيترات در ه دقيقه اول واكنش و بيشترين مقدار حذف نيترات كه بr 9. بوده است در طى •r دقيقه اول واكنش صورت گرفته است كه بعد از اين زمان حذف نيترات مقدار اندكى كاهش يافته ولى اين مقدار كاهش هيجگًاه از مقدار حذف قبل از از زمان

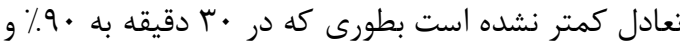

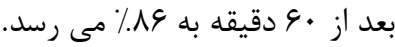
تاثير غلظت نيترات در حذف نيترات با مخمر: نتايج نشان دادكه حذف نيترات در غلظت هاى يايين در زمان تعادل و شرايط اسيدى بهتر صورت مى گيرد بطوريكه در غلظت

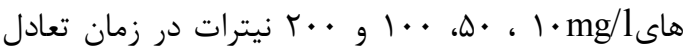

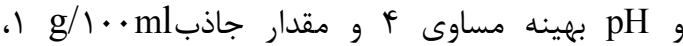

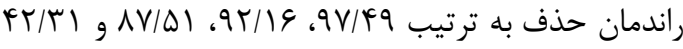
درصد بدست آمده است كه بيشترين راندمان مربوط به به به غلظت mg/l · • ا نيترات بوده است. تاثير مقدار جاذب در حذف نيترات با مخمر: در اين

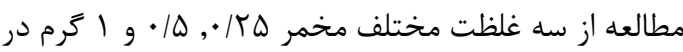

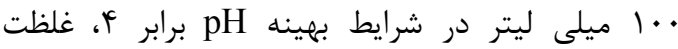

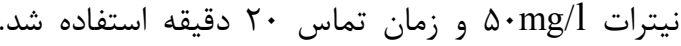

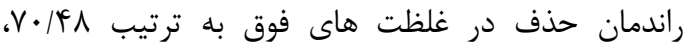

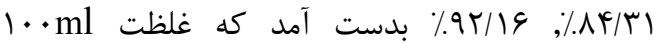
إبالاترين راندمان حذف را داشت. با توجه به نمودار شماره f ب با افزايش مقدار جاذب راندمان ران رذف نيترات افزايش مى يابد زيرا با افزايش مقدار جاذب سطح تماس ذرات نيز افزايش يافته و ميزان بيشترى از نيترات توسط مخمر حذف مى كردد.

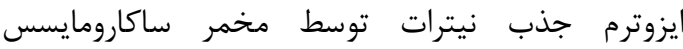
سرويسيه: ايزوترم جذب يكى از فاكتورهاى بسيار تاثير گذار در طراحى سيستم هاى جذب است. در حقيقت ايزوترم

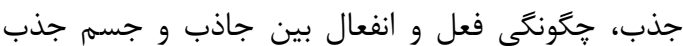
شونده را تشريح مى كند، بنابراين در بهينه نمودن مصرف يك جاذب و تعيين ميزان ظرفيت جذب نقش بسيار مهرمى دارند. مدل هاى ايزوترمى فروندليج و لانتمير بطور گَترده اى مورد استفاده قرار گرفته اند. ايزوترم هاى جذب به منظور تعريف جرم جذب شده از ماده جذب 
جذب از معادله درجه دوم پِيروى مى كند. در نهايت

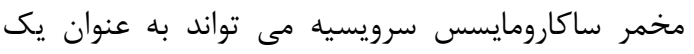

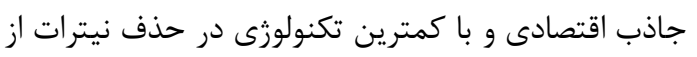
محلولهاى آبى مورد استفاده قرار تيرد.

\section{تشكر و قدردانى}

اين مقاله حاصل طرح تحقيقاتى با كد ودانى

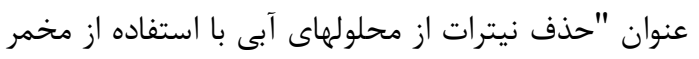

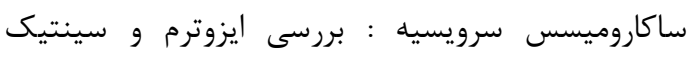

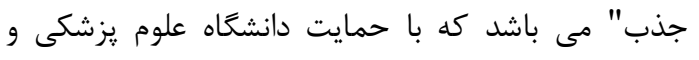

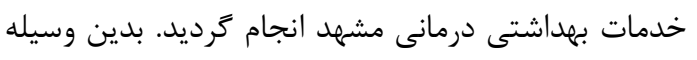
نويسند محترم يزوهشى دانشعاه به لحاظ حمايت مالى ثروزه اعلام

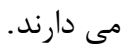

محاسبه شده Kf برابر با I / / • مى باشد و مقدار عددى

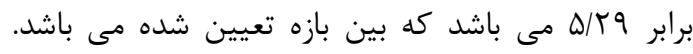

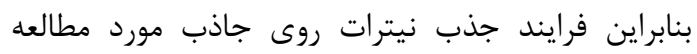
مناسب مى باشد

سينتيك جذب نيترات توسط مخمر ساكارومايسس سرويسيه: مطالعات سينتيك جذب جات بات اختلاط غلظت

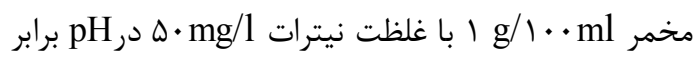

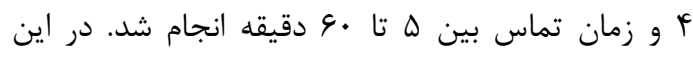

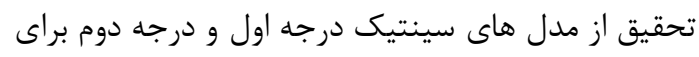
توصيف داده هاى حاصل استفاده شد. معادله (f) فرم خطى معادله درجه يك راد أنشان مى دهد: $\ln \left(1-\frac{q_{t}}{q_{g}}\right)=-k_{1} t$

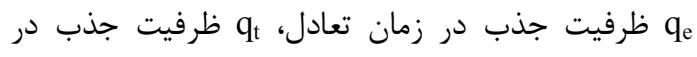

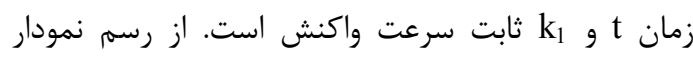
آيد

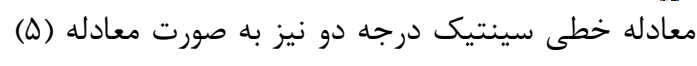
است كه با رسم $\frac{t}{q_{t}}=\frac{1}{K_{1} q_{z}^{2}}+\frac{1}{q_{z}} t$

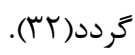

در مطالعه حاضر سنتيك جذب نشان داد كه جذب نيترات

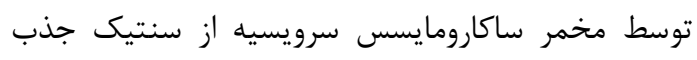

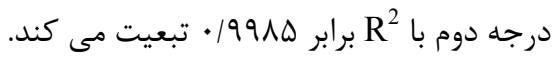

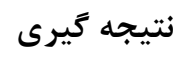
نتايج اين مطالعه نشان داد كه ميزان حذف نيترات توسط

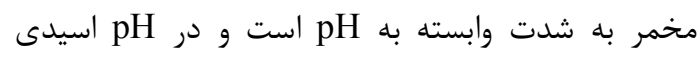

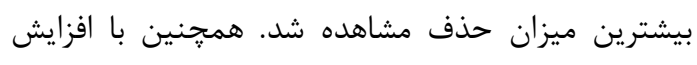

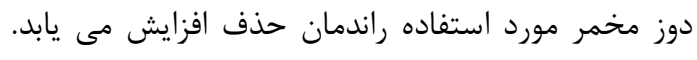

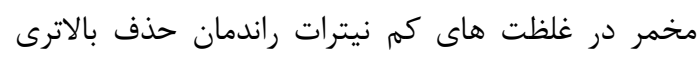

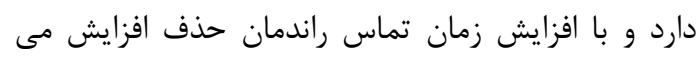

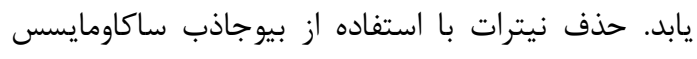

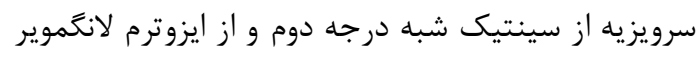

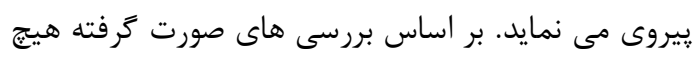

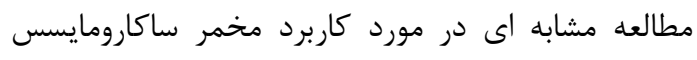

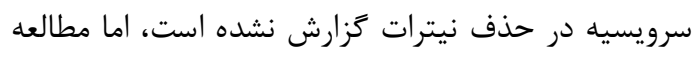

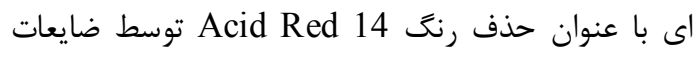

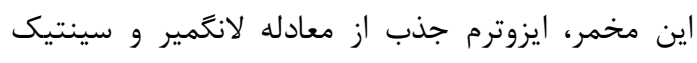




\section{References}

1. Alighadri M, Hazrati S, Sakhaiezadeh A, Soleymanpoor M, Measurement of Nitrate Concentrations in Drinking Water Supply Sources and Distribution Network of Ardabil City, Journal of Ardabil University of Medical Sciences, 2011;2(2):69-75[Persian].

2. Shrimali M, Singh K, New methods of nitrate removal from water, Environmental Pollution, 2001;112(3):351-9.

3. Wang J, Chen C, Biosorption of heavy metals by Saccharomyces cerevisiae: A review, Biotechnology advances, 2006;24(5):427-51.

4. $\mathrm{Xu} \mathrm{L}$, Niu $\mathrm{H}, \mathrm{Xu}$ J, Wang $\mathrm{X}$, NitrateNitrogen Leaching and Modeling in Intensive Agriculture Farmland in China, The Scientific World Journal, 2013;2013:1-10.

5. Izanloo $\mathrm{H}$, Rahimi $\mathrm{T}$, Mahmoudian $\mathrm{MH}$, Khazaei M, Yavari Z, Asgari AR, "et al", Nitrate Removal from Water Using Granules Ferric Hydroxide Absorbent, Health System Research. 2011(6):952-9[Persian].

6. Aslan S, Turkman A, Nitrate and pesticides removal from contaminated water using biodenitrification reactor, Process biochemistry, 2006;41(4):882-6.

7. Torabian A, Hasani AH, Samak Abedi M, Comparison of nitrate removal from drinking water by reverse osmosis and ion exchange, Journal of Environmental Science and Technology, 2006;8(3):21-8[Persian].

8. Cengeloglu Y, Tor A, Ersoz M, Arslan G, Removal of nitrate from aqueous solution by using red mud, Separation and Purification Technology, 2006;51(3):374-8.

9. Organization $\mathrm{WH}$, Guidelines for drinkingwater quality: recommendations: World Health Organization; 2004.

10.Ayyasamy PM, Shanthi K, Lakshmanaperumalsamy P, Lee S-J, Choi N-C, Kim D-J, Two-stage removal of nitrate from groundwater using biological and chemical treatments, Journal of bioscience and bioengineering, 2007;104(2):129-34.

11.Öztürk N, Bektaş Tel, Nitrate removal from aqueous solution by adsorption onto various materials, Journal of hazardous materials, 2004;112(1):155-62.

12.Aslan Ş, Türkman A, Combined biological removal of nitrate and pesticides using wheat straw as substrates, Process biochemistry, 2005;40(2):935-43.
13.Torabian A, Shokouhi Harandi M, Nabi Bidhendi G, Ghadimkhani A, Safaefar M, Evaluation of Efficiency Nitrate Removal of a Nanofiltration Membrane from Drinking Water under Different Operating Conditions, Water and Wastewater Consulting Engineers Research Development, 2007;18(61):1523[Persian].

14.Fallahi F, Ayati B, Ganjidoust H, Lab Scale Study of Nitrate Removal By Phytoremediation, Water and Wastewater Consulting Engineers Research Development, 2011;1:57-65[Persian].

15. Farasati $M$, Jafarzadeh $N$, Use of Agricultural Nano Adsorbents for Nitrate Removal from Aqueous Solutions, Iran-Water Resources Research,2013;8(3):11[Persian].

16. Rahmani ar, Soleymani $\mathrm{m}$, Removal of

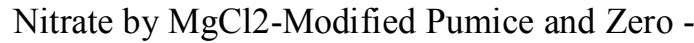
Valent Magnesium from Aqueous Solutions, Iranian Journal of Health and Environment 2010;4(3):14[Persian].

17.Apha A, Wef. . Standard Methods for the Examination of Water and Wastewater Washington: American Public Health Association; 2012;4-122.

18. Ghaneian MT, Ghanizadeh G, Gholami M, Ghaderinasab F, Application of Eggshell as a Natural Sorbent for the Removal of Reactive Red 123 Dye from Synthetic Textile Wastewater, Tabib shargh, 2009;11(4):2433[Persian].

19. Ghanizadeh G, Asgari G. Removal of Methylene Blue Dye from Synthetic Wastewater with Bone Char. Iranian Journal of Health and Environment, 2009;2(2):10413[Persian].

20.Li Y, Liu F, Xia B, Du Q, Zhang P, Wang $\mathrm{D}$, "et al", Removal of copper from aqueous solution by carbon nanotube/calcium alginate composites, Journal of hazardous materials, 2010;177(1):876-80.

21.Naddafi K, Nabizadeh Nodehi R, Jahangiri $\operatorname{rad}$ M, Removal of Reactive Blue 29 Dye fromWater by Single-Wall Carbon Nanotubes, Iranian journal of health and environment, 2011;3(4):359-68[Persian].

22.Farah JY, EL-Gendy NS, Performance, kinetics and equilibrium in biosorption of anionic dye Acid Red 14 by the waste biomass of Saccharomyces cerevisiae as a low-cost biosorbent, Turkish Journal of Engineering \& Environmental Sciences. 2013;37(51):16. 
23.Wang J, Chen C, Biosorbents for heavy metals removal and their future, Biotechnology advances, 2009;27(2):195-226.

24.Arabi F, Asadi g, Removal of nitrate by zeolite modified with cationic sorfactant, national conferance on environmental health, 2013;16(1):14[Persian].

25.Esmaili A, Nasseri S, Mahvi AH, Atash Dehghan R, Removal of Copper and Nickel from Aqueous Solutions by Natural Bentonite, Journal of Rafsanjan University of Medical Sciences 2002;2(1):22-30[Persian].

26.Golbabaei F, Ghahri A, Soudi MR, Rahimi Forushani A, Tirgar A, Equilibrium and kinetic studies of biological uptake of hexavalent chromium from aqueous solution using xanthan polymer granules B82, Iranian Journal of Chemistry \& Chemical Engineering, 2011;30(2):11-24[Persian].

27.Khorramfar S, Mahmoodi NM, Arami M, Gharanjig K, Dye Removal from Colored Textile Wastewater Using Tamarindus Indica Hull: Adsorption Isotherm and Kinetics Study, Journal of Color Science and Technology, 2009;3:81-8[Persian].

28. Malakootian M, Hashemi Chalicheh M, The efficiency of photocatalytic process by silica nanoparticles compared with zirconia-for the removal of bivalent nickel from aqueous solution and determine the optimum conditions the removal, Journal of Mazandaran University of Medical Sciences 2012;22(93):87-96.

29. Malakootian M, Moussavi SG, Toolabi A, A Study of kinetics And Biosorption Isotherms of Heavy Metals By Algae Ulothrix Zonata from Industrial Wastewater, Scientific Journal of Ilam University of Medical Sciences, 2011;19(4):26-37[Persian].

30.Nameni M, Alavi Moghaddam SM, Arami M, Study of adsorption equilibrium of chromium hexavalent from aqueous solution using rice bran, Journal of Environmental Science and Technology 2007;10(4):184-95.

31. Saeidi M, Pajuhesh Far S,Evaluation phenol adsorption from contaminated water using activated carbon and carbon of almond and walnut shell, Journal of Environmental Science and Technology,2007;10(4):218-31[Persian].

32. Shi Z, Zhang Y, Zhou J, Chen M, Wang X, Biological removal of nitrate and ammonium under aerobic atmosphere by Paracoccus versutus LYM, Bioresource technology, 2013;148:144-8. 


\title{
Removal of nitrate from aqueous solutions using Saccharomyces cerevisiae biosorbent: Adsorption isotherms and kinetics
}

\author{
Nemati sani $O^{l}$, Sadeghi $A^{2 *}$, Dehghan A. $A^{3}$, Asadzadeh S. $N^{4}$, Dolatabadi $M^{\prime}$ \\ ${ }^{1}$ M.Sc. in Environmental Health Engineering, student research committee, Mashhad University of Medical \\ Sciences, mashhad, Iran. \\ ${ }^{2}$ Assistant Professor, Member of Health Sciences Research Center of, Department of Environmental Health \\ Engineering, Health School, Mashhad University of Medical Sciences, Mashhad, Iran. \\ ${ }^{3} \mathrm{PhD}$ student of Environmental Health Engineering, Department of Environmental Health Engineering, Health \\ School, Mashhad University of Medical Sciences, Mashhad, Iran. \\ ${ }^{4}$ Graduate Student of Environmental Health Engineering, North Khorasan University of Medical Sciences, \\ Bojnurd, Iran.
}

$\begin{array}{lr}\text { *Corresponding } & \text { Author: } \\ \text { Health School, } & \text { Mashhad } \\ \text { University of } & \text { Medical }\end{array}$

Sciences, Mashhad, Iran.

Email: sadeghia@mums.ac.ir

\begin{abstract}
Background and Objectives:Nitrate is one of the pollutants of drinking water. High nitrate concentration in water is considered as a serious threat. When nitrate concentration exceeds from the standard (50 $\mathrm{mg} / \mathrm{l}$ as $\mathrm{NO}_{3}$ ) in drinking water, it can cause methemoglobinemia in children, and also the formation of carcinogenic nitrosamines. To the best of our knowledge, no related study has been performed to use Saccharomyces cerevisiae for nitrate removal. In this study we investigate the possibility of using Saccharomyces cerevisiae as a low cost candidate for nitrate removal from aqueous solutions.

Materials and Methods: This research is a laboratory study. We studied the influence of process variables such as adsorbent dose, initial $\mathrm{NO}_{3}$ concentration, $\mathrm{pH}$ and contact time on adsorption process. Langmuir and Freundlich isotherms and adsorption kinetic was also studied.

Results:Most of the experiments were done with $50 \mathrm{mg} / \mathrm{l}$ of initial nitrate. Our results showed that the maximum $\mathrm{NO}_{3}$ removal efficiency was achieved at $\mathrm{pH}=4$, adsorbent dose $1 \mathrm{~g} / 100 \mathrm{ml}$ and contact time $20 \mathrm{~min}$. The result showed that the nitrate absorption by the Saccharomyces cerevisiae followed Langmuir isotherm and second-order kinetics.

Conclusion:According to the results of this study Saccharomyces cerevisiae can be a suitable and economical candidate for the removal of nitrate with minimal technology.

Keywords: Nitrate; Saccharomyces cerevisiae; Aqueous solutions; Kinetic; Isotherm
\end{abstract}

Submitted:23 Apr 2014

Revised:17 June 2014

Accepted:2 Aug 2014 